\title{
A RELAÇÃO ENTRE A BRINCADEIRA DE FAZ-DE CONTA E O DESENVOLVIMENTO DE HABILIDADES NA AQUISIÇÃO DE UMA TEORIA DA MENTE
}

\author{
Ana Claudia da Silva Alves \\ Maria das Graças Bompastor Borges Dias" \\ Avany Bernardino Corrêa Sobral
}

\begin{abstract}
RESUMO. Neste artigo estuda-se a relação entre algumas operações básicas no desenvolvimento de uma teoria da mente, como ferramenta de interação, e habilidades que baseiam a brincadeira de faz-de-conta. Entende-se por teoria da mente o conjunto de habilidades que permitem à criança compreender, fazer referências e considerar estados mentais próprios e dos outros e diferenciá-los, operando socialmente a partir desta compreensão. Por brincadeira de faz-de-conta entende-se um setting de ação lúdica em que a criança opera num domínio imaginário, que não se limita nem corresponde à realidade concreta. Com base em alguns pressupostos já abordados na literatura sobre a relação entre o desenvolvimento de habilidades sociocognitivas e a aquisição uma teoria da mente, discute-se a observação e analise de uma interação comunicativa entre uma criança ( 3,9 anos) e sua mãe. Evidencia-se que os jogos de faz-de-conta constituem-se como setting para a flexibilização do pensamento e surgimento de habilidades primordiais no desenvolvimento de uma teoria da mente.
\end{abstract}

Palavras-chave: faz-de-conta, teoria da mente, interação.

\section{THE RELATIONSHIP BETWEEN MAKE-BELIEVE PLAY AND THE DEVELOPMENT OF ABILITIES TO ACQUISITION OF THEORY OF MIND}

\begin{abstract}
This article examines the relationship between some basic operations of the development of a theory of mind, as an interactional tool, and abilities that base the make-believe play. Theory of mind is understood as a conjunct of abilities that equips a child to comprehend, make references, and also consider own and other's mental states, differentiating them and socially operating through this comprehension. Make-believe play is understood, in this study, as a setting of playful action in which a child operates in an imaginary dominion, that it is neither limited to the concrete reality nor equivalent to it. Based in some assumptions, previously approached by many authors, about the relationship between the development of sociocognitive abilities and the acquisition a theory of mind, the observation and analysis of a communicative interaction between a 3.9-yearold child and his mother is discussed. Through some evidences, it is demonstrated that make-believe games constitute a setting that promotes flexibility of thinking and the appearance of some abilities meanly important to the development of a theory of mind.
\end{abstract}

Key words: Make-believe, theory of mind, interaction.

\section{LA RELACIÓN ENTRE EL JUEGO DE SIMULACRO INFANTIL Y EL DESARROLLO DE COMPETENCIAS EN LA ADQUISICIÓN DE UNA TEORÍA DE LA MENTE}

\begin{abstract}
RESUMEN. Este artículo presenta un análisis de la relación entre operaciones básicas para el desarrollo de una teoría de la mente y algunas competencias que dan bases al juego de simulacro. Definimos teoría de la mente como un conjunto de habilidades que le permite al niño comprender, mencionar y considerar los propios estados mentales, así como los de los otros, accionando socialmente por medio de esta comprensión. Como juegos de simulacro definimos un setting de acción lúdica en el cual el niño opera en un dominio imaginario, que no se limita, ni corresponde a la realidad concreta. Con base en algunas premisas anteriormente exploradas en la literatura sobre la relación entre el desarrollo de habilidades socio-cognitivas y la adquisición de una teoría de la mente, discutimos la observación y análisis de una interacción comunicativa entre un niño (3,9 años) y su madre. Las evidencias presentadas demuestran que los juegos de simulacro se constituyen como setting para la flexibilización del pensamiento y también para el surgimiento de competencias importantes para el desarrollo de una teoría de la mente.
\end{abstract}

Palabras-clave: juegos de simulacro, teoría de la mente, interacción.

* Mestre em Psicologia pela Universidade Federal de Pernambuco-UFPE.

\# Doutora. Professora da Pós-graduação em Psicologia, Universidade Federal de Pernambuco-UFPe. 
O desenvolvimento de competências cognitivas que baseiam as interações sociais das crianças tem sido objeto de estudo da psicologia cognitiva desde que a ciência psicológica passou a reconsiderar as operações mentais como parte de seus objetos de estudo. Embora ao longo do desenvolvimento desta área novas perspectivas e modelos explicativos tenham surgido, um dos eixos que une diferentes abordagens neste campo de pesquisa tem sido o objetivo de avançar na compreensão de como sujeitos, especialmente crianças pré-escolares, desenvolvem e fazem uso de uma compreensão sobre os estados mentais próprios e dos outros. Questões ligadas à gênese, natureza e funcionamento das habilidades nomeadas como parte de uma teoria da mente são pontos que têm dividido pesquisadores em diferentes linhas de pesquisa.

Há, entre as diferentes abordagens, um posicionamento teórico que atribui às relações interpessoais que o sujeito estabelece com o mundo social o conhecimento das pessoas como possuidoras de uma mente e os processos que a envolvem. Neste tipo de abordagem não se desconsidera, necessariamente, outros fatores agentes no desenvolvimento de uma teoria da mente, mas considera-se a psicologia popular como um set de práticas e convenções culturais e sociais (Astington \& Gopnik, citado por Jou \& Sperb, 1999). A formação da teoria da mente seria, então uma forma de entrada em um mundo em que símbolos e signos são condições necessárias na interação. Pertencer à cultura seria, portanto, condição necessária no desenvolvimento de uma teoria da mente. Compactuar com esta visão sobre o desenvolvimento de uma teoria da mente não exclui, necessariamente, outros aspectos do desenvolvimento das habilidades reunidas nesta capacidade, mas direcionam a teoria da mente como existente para a cultura e a partir da cultura. Para a cultura, por ter como objetivo mediar as relações do sujeito com o mundo da coletividade e a partir da cultura, porque se constrói na coletividade, na relação com o outro e com as ferramentas socialmente construídas. Tendo como base esta visão, é possível pensar nas atividades sóciohistoricamente construídas, entre elas as narrativas e brincadeiras infantis, como portadoras de significados culturais que possibilitam a sedimentação de ferramentas sociais necessárias nas interações sociais.

Embora estudos em teoria da mente constituam uma área de investigação recente, se comparada com outras áreas dentro do campo da cognição humana, investigações com o objetivo de ampliar o debate sobre a compreensão da criança em relação à mente e desenvolver modelos explicativos é bastante tradicional na ciência psicológica.

Piaget (1929) é considerado o primeiro autor a se interessar por esta temática, isto, por haver se dedicado a investigar sobre a compreensão de estados mentais por parte das crianças e a diferenciação que estas fazem destes para os estados físicos.

Em A linguagem e o Pensamento da Criança, Piaget (1956) diferencia a linguagem infantil em dois 'momentos'. Inicialmente, a fala da criança seria marcada pelo egocentrismo que, num segundo momento, seria superado gradual e maturacionalmente, dando lugar à emersão de uma fala socializada.

Além do papel da linguagem em teoria da mente ser um tema recorrente e amplamente discutido, alguns estudos partem da concepção de que a linguagem seria "uma janela aberta" sobre esse desenvolvimento, embora haja também aqueles (Shatz, Silber \& Wellman, 1993, dentre outros) que afirmam que o uso de termos mentais não seria suficiente para atestar a existência de uma teoria da mente. No entanto, considerar o papel da linguagem no desenvolvimento de uma teoria da mente como algo atestado apenas pelo uso ou não de termos mentais é de certa forma reducionista. É possível pensar na linguagem não apenas como um instrumento a partir do qual as crianças explicitam seus insights sobre estados mentais, mas também como parte primordial na mediação das relações da criança com o mundo.

Ao falar sobre a linguagem, não pretendemos restringi-la apenas a verbalização, mas mesmo quando abordando este aspecto, as trocas comunicativas das crianças através da fala apresentam outros elementos para além da utilização de termos mentais que evidenciam a importância das trocas lingüísticas e interações sociais, tanto no processo de desenvolvimento de uma teoria da mente, como no que diz respeito ao papel desempenhado por esta habilidade.

Como afirmamos anteriormente, neste estudo temos como objetivo analisar um episódio ocorrido em uma situação observada em que mãe e criança elaboram juntas um desenho e estabelecem um diálogo a partir deste. É importante ressaltar que a análise feita a seguir não tem como objetivo uma busca exaustiva e classificação contextual de termos referentes a estados mentais. O objetivo assumido é o de perceber importantes elementos que a interação da criança com o adulto e o jogo imaginário trazem para a construção de uma compreensão implícita da mente e das operações possíveis de realização a partir do pensamento. 
Em síntese, a relação estabelecida entre teoria da mente e brincadeira de faz-de-conta tem como foco a interação e o compartilhar de signos culturais que esta atividade demanda. Compreendendo a teoria da mente como processo de inclusão social, ligada ao desenvolvimento de uma subjetividade por parte do sujeito (premissa que discutiremos a seguir), ressaltamos que o interesse deste estudo não é o emprego de termos mentais, a ausência ou presença de uma teoria da mente, mas sim o uso de habilidades importantes, que estão na base de uma teoria da mente tais como flexibilização do pensamento, possibilidade de descentrar-se e inferir acerca do ponto de vista do outro. Portanto, o foco dado às interações comunicativas, aos contextos emergentes a que estas dão origem e ao papel da relação com o outro são justificados pelo interesse em perceber mecanismos e elementos que relacionam teoria da mente $\mathrm{e}$ brincadeiras de faz-de-conta.

\section{TEORIA DA MENTE COMO PROCESSO DE INCLUSÃO CULTURAL}

No presente estudo, partiu-se do pressuposto de que a teoria da mente é uma aquisição importante e emerge do próprio processo de subjetivação do sujeito. Esta habilidade permitiria à criança diferenciar-se do outro, percebendo-se como sujeito que possui seus próprios pensamentos, intenções, sentimentos e crenças que a tornam um agente social. Ao mesmo tempo, habilidades consideradas como parte de uma teoria da mente integrariam a inclusão da criança na coletividade, pois a partir desta compreensão implícita e construção de conceitos sobre o funcionamento dos processos mentais a criança passa a fazer generalizações sobre estados mentais, construindo, assim, modelos de funcionamento mentais que utilizará em suas interações com outros agentes sociais.

Ao abordar o desenvolvimento a partir de um paradigma sócio-histórico, não estamos ignorando elementos outros, como os aspectos biológicos do desenvolvimento, mas considerando que, como afirma Furtado (2002, p. 79-80), "a própria biologia passa a ter caráter sócio-histórico, na medida em que a adaptação caminhará apoiada nos caminhos escolhidos pelo próprio homem" e ainda que "(...) o homem por suas características sócio-históricas, não nasce pronto. Cada indivíduo aprende a ser um homem".

Neste processo, a linguagem seria importante na apropriação das operações que são historicamente construídas, sendo, portanto, a comunicação (não apenas escrita ou falada, mas presente nos gestos, posturas e trocas) condição necessária e específica do desenvolvimento do homem na sociedade.

Como podemos compreender, neste enquadre teórico, não se assume uma visão semelhante à behaviorista do desenvolvimento como uma imposição ambiental, mas como uma construção que não subsiste para além da cultura, compreendida como uma construção social, mas ao mesmo tempo singular, na qual a linguagem teria um papel central. O sujeito psicológico não teria sua gênese numa influência do externo, mas num processo entre o objeto e o indivíduo.

Abordando a teoria da mente a partir desta visão de desenvolvimento faremos a análise de um trecho em que criança e a mãe constroem um espaço de brincadeira de faz-de-conta e troca de papéis.

\section{Alguns estudos sobre brincadeiras de faz-de-conta}

No trecho de diálogo que analisaremos, faz-se uma tentativa de discutir alguns elementos na brincadeira de faz-de-conta que apontam para a importância desta atividade no desenvolvimento de uma teoria da mente, tema abordado anteriormente por outros autores.

Leslie (1988a), embora parta de posicionamentos diferentes dos assumidos neste estudo, conceitua a brincadeira de faz-de-conta como uma atividade em que com um objeto ou ação a criança pode representar um outro objeto ou ação com distorção deliberada, da maneira como a situação é compreendida.

Embora não se faça necessário uma exaustiva revisão bibliográfica, podemos citar uma série de estudos realizados por Dias e Harris (1988a; 1988b; $1989 ; 1$ 1990a; 1990b; 1990c) em que os autores constataram que a apresentação de premissas num contexto em que se insere o faz-de-conta melhora o desempenho das crianças, de 3-4 a 5-6 anos de idade em raciocinar de maneira lógica, mesmo quando o conteúdo das premissas é desconhecido ou contrário a suas experiências do cotidiano.

Leslie (1987) concluiu que crianças de dois anos de idade já seriam capazes de raciocinar com conteúdos causais contrários as suas experiências, em um estudo acerca dos processos inferenciais em situações imaginárias. Uma outra posição assumida por Leslie (1988b) é de que o pensamento da criança vai, ao longo da infância, adquirindo poder de representar e raciocinar imaginativamente, o que forneceria a base para distinção entre aparência e realidade, importante no desenvolvimento das competências sociais.

A partir dos estudos apresentados, uma série de questões surge: Seria a brincadeira de faz-de-conta 
portadora de ferramentas precursoras no desenvolvimento de uma teoria da mente? Ou seria esta facilitadora de um processo de apreensão de uma teoria da mente por parte da criança? Seria possível a partir do faz de conta identificar operações mentais imprescindíveis no desenvolvimento de uma teoria da mente?

Neste estudo utilizaremos como objeto central de discussão o discurso espontâneo de uma criança em processo de interação com sua mãe. O interesse no diálogo está centrado em elementos que evidenciam a idéia de que nas relações sociais são utilizadas ferramentas sociais que apontam para a sedimentação de habilidades reconhecidas como parte de uma teoria da mente. Defende-se, portanto, a idéia de que situações sociais estabelecem um set de práticas que dá conta do uso de certas habilidades que posicionam a criança numa relação e papel que requer considerar que o outro pode vir a pensar, imaginar, sentir e entender diferente dela.

Sendo a situação apresentada categorizada como brincadeira de faz-de-conta ou jogo imaginário, faz-se importante explicitar que neste trabalho estamos considerando a situação de faz-de-conta ou jogo imaginário uma atividade que demanda da criança a possibilidade de descentra-se da realidade concreta, para operar numa realidade paralela, imaginária. O jogo imaginário é, portanto, considerado como atividade cultural portadora de significações sociais, contribuindo para inserção da criança no compartilhar dos signos e possibilidades sociais.

Silva, Guimarães, Vieira, Franck e Hippert (2005) apontam para o fato de que "a atividade mental de um ser humano não é isolada. (...) A vida mental é construída com os outros, ela é criada para ser comunicada e se desenvolve graças aos códigos culturais, às tradições" (p. 6). Os contos infantis, as brincadeiras e jogos compartilhados socialmente constituiriam, consequientemente, uma forma de inclusão social significativa. As autoras ainda apresentam a idéia defendida por Bruner (citado por Silva \& cols., 2005) de que a cultura seria importante no modo como uma criança se porta perante as aprendizagens, e que através das narrativas se sedimentaria uma concepção do que as pessoas são no universo. Em resumo, através das narrativas seriam fornecidos modelos de identificação e de ação que situariam o sujeito na cultura.

A brincadeira infantil vivenciada no jogo de fazde-conta tem um lugar social de atividade que permite criar, fantasiar, imaginar, e quando há parceiros de jogo, compartilhar o produto destas atividades com o outro. Nesta forma de interação emergiriam novas formas de entendimento da realidade. Alem disto, quando brincando com parceiros, também surgiria a necessidade de compartilhar com o outro esta realidade paralela construída no jogo imaginário. Alguns autores situam a habilidade de operar no domínio do faz-deconta como diretamente ligada à teoria da mente. Leslie (1988b), por exemplo, argumenta sobre a necessidade de entender quando o parceiro da brincadeira está fingindo para então entrar no domínio do faz-de-conta. Para ele, esta habilidade requereria o mesmo tipo de estrutura lógica que basearia a compreensão de estados mentais.

Além disto, sendo os dados posteriormente apresentados parte de uma interação comunicativa é possível também observar como a partir destas interações se desenvolve o que Bruner (1986) situa como sendo mais que aquisição de ferramentas para as operações cognitivas. Segundo este autor, ao fazer uso da linguagem para alcançar seus fins, as crianças têm mais do que domínio sobre um código comunicativo; elas negociam procedimentos e significados e quando fazem isto, estão aprendendo o caminho da cultura bem como o caminho da linguagem. Enfim, quando em suas interações comunicativas as crianças estabelecem com seus parceiros um setting de faz-de-conta, estabelecese uma estrutura interativa que dá suporte a entrada do sujeito na coletividade, a partir da possibilidade de compartilhar significados.

\section{MÉTODO}

Partindo dos objetivos propostos e descritos inicialmente neste trabalho, um trecho de interação entre uma criança e sua mãe foi selecionado dentre os dados de um estudo desenvolvido anteriormente. $\mathrm{O}$ estudo do qual os referidos dados fizeram parte teve por objetivo analisar o uso de termos mentais por parte de crianças em interação com seus pares e mães ${ }^{1}$. A metodologia selecionada e aplicada constitui-se, portanto, em uma análise de conversação na qual concentramos especial atenção na interação comunicativa e geração de contextos que emergiram a partir desta.

\footnotetext{
O estudo mencionado foi desenvolvido como dissertação de mestrado por uma das autoras e defendido em julho de 2003 como exigência para aquisição de grau de Mestre em Psicologia pela UFPe. A pesquisa se intitulou: $\mathrm{O}$ uso de termos mentais por crianças de 2.5 anos em interação com suas mães e pares e foi desenvolvida por Ana Claudia Alves, tendo como orientadora a Dra Maria Das Graças Bompastor Borges Dias, também autora deste estudo.
} 
Os dados selecionados para análise fizeram parte de quatro seções de interação da criança (duas com colega mais velha e duas com sua mãe). Utilizaremos como dados apenas um trecho de um dos encontros entre mãe, criança e pesquisadora.

Os participantes do estudo foram uma criança de 3.9 anos de idade e sua mãe. A criança era aluno do jardim da infância de uma pequena escola comunitária, sendo o mais novo de uma família de dois irmãos. A seção transcrita ocorreu na escola em que a criança estudava.

Durante o momento de interação registrado, foi disponibilizada à mãe e à criança uma série de materiais próprios para atividades manuais, tais como tesouras, revistas, lápis de cor, hidrocor, borrachas, lápis grafite, cartolinas e diversos tipos de papéis. $\mathrm{O}$ material fornecido teve o intuito de criar uma atividade em que mãe e criança se empenhassem e desenvolvessem interações comunicativas. Os dados selecionados para este estudo foram gravados em áudio (com um gravador) e também registrados em vídeo. A pesquisadora, presente no ambiente também desenvolveu um diário no qual registrou dados da interação.

Em um momento anterior a situação de interação registrada, houve um encontro informal com a mãe da criança a fim de que esta pudesse compreender os propósitos da tarefa propostas e tirar suas dúvidas sobre os objetivos do registro das seções que se transcorreriam entre ela e seu filho. Posteriormente, a orientação dada foi para que mãe e criança fizessem algo juntas com o material disponibilizado. Um dos pontos ressaltados no momento de orientação foi o fato de que não havia uma forma padronizada para que mãe e criança desenvolvessem sua atividade, ambos deveriam fazê-lo como desejassem.

Sendo o intuito deste estudo analisar a interação comunicativa de mãe e criança, dando especial destaque ao diálogo desenvolvido por ambos, os dados utilizados serão apenas os provenientes do registro em áudio e do diário de observação da pesquisadora presente no ambiente no momento em que a atividade desenvolveu-se.

A análise e discussão dos dados basearam-se em alguns pressupostos da análise de conversação2 e nas questões e posicionamentos anteriormente apresentados.

\section{ANÁLISE E DISCUSSÃO}

A fim de melhor fundamentar as idéias discutidas neste estudo, apresentaremos os dados que se

\footnotetext{
${ }^{2}$ Ver Pomerantz, A. e Feher, B.J. (1997).
}

constituem o cerne das idéias apresentadas neste estudo.

1- Igor: Terminei. Vou fazer uma casa agora.

2- Mãe: Tu só faz casa, né?- Ein? (pausa) Ah, já sei! Vai ser a casa de Chapeuzinho Vermelho.

3- Igor: É da vovó dela, né?

4- Mãe: Faz Chapeuzinho (pega o lápis da mão de Igor e começa a desenhar). Assim mãezinha. Aqui é a casa dela (continua a desenhar). Ela vai pra onde? Aqui na floresta é casa de quem? Pra onde chapeuzinho vai?

5- Igor: É a casa da vovó

6- Mãe: Vamos botar o nome dela (escreve com a mão de Igor por baixo da dela) Chapeuzinho...

7- Igor (complementando fala da mãe): Vermelho. (pausa). Mãe, faz o lobo mau. (pausa) Cadê? Abre a porta! Tem que abrir pro lobo entrar!

8- Mãe: Mas essa porta é só do desenho! É de papel, mãezinha, porta de papel não abre!

9- Igor: Abre sim, que o lobo vai comer a vovó e Chapeuzinho Vermelho!

10- Mãe: Mas é na história, aqui nós tá brincando de faz que é, tá?

11- Igor: Então abre a porta de mentirinha!

12- Mãe: De mentirinha pode, sim! (Trecho inaudível) trin, trin! Vovó (engrossando a vos) venha abrir a porta!

13- Igor: Abre não, vovó! É o lobo! Ele é do mal!

14- Mãe: Ah! A vovó abriu!! E agora? Ele comeu a vovó!

15- Igor: Ela abriu a porta! Não é pra abrir! Ela não é sabida! A tia dela num disse pra não pra não abrir a porta, foi?

16- Mãe: Mas ela acha que é Chapeuzinho, coitada da vovó.

17- Igor: Coitada! O lobo comeu ela inteirinha.

18- Mãe: Foi, mãezinha! Coitada da vovó!

O fragmento da interação selecionado como elemento de análise inicia-se quando, após terminar um desenho, a criança explicita para a mãe a intenção de começar um outro desenho:

$$
\text { Igor: Terminei. Vou fazer uma casa agora. }
$$

A mãe de Igor responde situando a ação da criança como repetida e propondo dar um significado diferenciado ao desenho:

Mãe: Tu só faz casa, nê?- Ein? (pausa) Ah, já sei! Vai ser a casa de Chapeuzinho Vermelho. 
Ao fazer isto a mãe utiliza a possibilidade existente nas atividades em que se utiliza o simbolismo de gerar significados. O desenho feito por Igor e sua mãe, deixa de ser mais uma casa que ele desenha e passa a ser a casa de um personagem de uma história infantil conhecida de ambos. Neste momento a mãe propõe a Igor que o seu desenho seja parte do cenário de uma história de faz-de-conta, ato a partir do qual se torna possível o desenrolar do script de uma história.

Após a inserção desta significação feita pela mãe e a nomeação da ilustração, a mãe passa a direcionar o diálogo, incluindo outros elementos e personagens, construindo o cenário e o elenco do clássico infantil (Chapeuzinho Vermelho, casa de Chapeuzinho Vermelho, casa da avó), nomeando-os e fazendo perguntas à criança, que passa a respondê-las a partir de pistas maternas, colaborando na construção do set da história.

A mãe por sua vez, não desenvolve a atividade sozinha, embora a princípio ela e Igor não compartilhassem do mesmo significado para a casa inicialmente desenhada (ver falas 2 a 5 nas quais os dados transcritos demonstram que, inicialmente, Igor designa a casa para ser a casa da vovó e a mãe continua a tratá-la como sendo a casa de Chapeuzinho Vermelho). Além de incluir novos elementos, a mãe constantemente envolve a criança na atividade, convidando-o a desenhar personagens, a fazer objetos e fazendo um certo jogo, dando pistas a partir das quais a criança nomeia elementos inseridos no cenário da história:

\section{Exemplo:}

4- Mãe: Faz chapeuzinho (pega o lápis da mão de Igor e começa a desenhar) Assim mãezinha. Aqui é a casa dela (continua a desenhar). Ela vai pra onde? Aqui na floresta é casa de quem? Pra onde chapeuzinho vai?

5- Igor: É a casa da vovó.

6- Mãe: Vamos botar o nome dela (escreve com a mão de Igor por baixo da dela) Chapeuzinho...

No momento da interação apresentado, mãe e criança assumem a tarefa de desenhar o cenário da história; a mãe convida Igor a nomear os elementos desenhados a partir da história infantil trazida por esta à brincadeira. Além dos elementos do cenário, a mãe passa a fazer perguntas a Igor sobre trechos da história que ocorrem no cenário já construído no desenho. Igor e a mãe trabalham no desenho como quem constrói um cenário para uma representação, no qual uma história terá o seu desenrolar:
- A casa de chapeuzinho:

Mãe: (...) Assim, mãezinha. Aqui é a casa dela.

- A floresta e a casa da vovó:

4-Mãe: Faz Chapeuzinho (pega o lápis da mão de Igor e começa a desenhar). Assim, mãezinha. Aqui é a casa dela (continua a desenhar). Ela vai pra onde? Aqui na floresta, é casa de quem? Pra onde chapeuzinho vai?

5-Igor: É a casa da vovó.

6-Mãe: Vamos botar o nome dela (escreve com a mão de Igor por baixo da dela) Chapeuzinho...

Enquanto inclui elementos no cenário, a mãe faz perguntas a Igor que envolve personagem (Chapeuzinho Vermelho), conferindo-lhe possibilidades de ação, em um contexto de faz-deconta, perguntando para onde Chapeuzinho Vermelho vai. Neste momento parece haver uma mudança de papéis e tarefas. Igor e a mãe agregam à posição de construção do cenário a de narradores da história, a partir de personagens que passam a ser inseridos, sendo também incluída a possibilidade existente no contexto de faz-de-conta de animação dos personagens. Em um primeiro momento a mãe faz pergunta sobre a ação de chapeuzinho presente no script desse personagem da história. Em seguida, Igor passa a perguntar pelos demais personagens e pelo efeito necessário para que a narrativa transcorra seguindo a seqüência do conto (na história, a porta é aberta pela vovó para que o lobo entre) e que os personagens desempenhem as ações seguintes:

\section{- 5-Igor: É a casa da vovó}

- 6-Mãe: Vamos botar o nome dela (escreve com a mão de Igor por baixo da dela) Chapeuzinho...

- 7-Igor (complementando fala da mãe): Vermelho. (pausa). Mãe faz o lobo mau. (pausa) Cadê? Abre a porta! Tem que abrir pro lobo entrar!

Ao solicitar que a mãe "abra a porta", Igor segue a sequiência dos fatos da história (a vovó abre a porta e o lobo entra) afirmando que, para que o fato seguinte aconteça (o lobo entre e coma a vovó), a porta precisa ser aberta. No momento seguinte ocorre uma quebra no ambiente de animação, quando a mãe sai da brincadeira para a concretude do desenho (a porta é desenhada, de papel) e apresenta um fator que os impossibilita de desenvolver a ação que a criança solicita. Anteriormente, a mãe e Igor desenvolviam ações no domínio do imaginário da história infantil, mas neste momento o questionamento da mãe traz a brincadeira para o domínio da realidade objetiva: 
8- Mãe: Mas essa porta é só do desenho! É de papel mãezinha, porta de papel não abre.

A criança responde a esta quebra de contexto, mostrando a necessidade de que o fato previsto no script da história ocorra para que a ação continue se desenrolando:

9- Igor: Abre sim, que o lobo vai comer a vovó e Chapeuzinho Vermelho!

A criança então renegocia com a mãe a forma como aquela ação pode se dar: no domínio da brincadeira de faz-de-conta em que abrir uma porta desenhada sem de fato abri-la na ação concreta é possível:

9- Igor: Abre sim, que o lobo vai comer a vovó e Chapeuzinho Vermelho!

10- Mãe: Mas é na história, aqui nós ta brincando de faz que é, ta?

11- Igor: Então abre a porta de mentirinha!

12- Mãe: De mentirinha pode, sim! (Trecho inaudivel) trin, trin! Vovó (engrossando a voz) venha abrir a porta!

A mãe retorna ao formato inicial da brincadeira e aceita o movimento da porta como algo que não é possível em uma realidade objetiva, mas sim no contexto de faz-de-conta (mentirinha, como proposto por Igor) e passa a simular o som de objetos e timbres de voz na animação da história.

Transcorrido este momento da interação, segue-se um outro em que Igor, tal qual quem assiste a uma peça, filme, etc. assume o papel de espectador da história, torcendo e dando dicas à vovó. A criança passa de parceiro da mãe a espectador da encenação realizada por esta, fazendo, inclusive, críticas ao comportamento do personagem:

12- Mãe: De mentirinha pode, sim! (Trecho inaudivel) trin, trin! Vovó (engrossando a voz) venha abrir a porta!

13- Igor: Abre não, vovó! É o lobo! Ele é do mal!

14- Mãe: Ah! A vovó abriu!! E agora? Ele comeu a vovó!

15- Igor: Ela abriu a porta! Não é pra abrir! Ela não é sabida! A tia dela num disse pra não pra não abrir a porta, foi?

No momento seguinte, Igor mostra-se penalizado pelo desfecho da cena:

16-Mãe: Mas ela acha que é Chapeuzinho, coitada da vovó!

17-Igor: Coitada! O lobo comeu ela inteirinha. 18-Mãe: Foi, mãezinha! Coitada da vovó!
A partir dos dados descritos, pode-se perceber a importância da brincadeira de faz-de-conta para o desenvolvimento de habilidades centrais no desenvolvimento de uma teoria da mente por parte da criança. Ao afirmar isto, não pretendemos situar este tipo de brincadeira como atividade condicional, mas como uma atividade em que estão presentes elementos enquadrados na literatura como parte do desenvolvimento de uma teoria da mente. Nos trechos anteriores, verifica-se como o faz-de-conta permite estabelecer uma ação em um acordo simbólico em que o sujeito situa sua ação a partir de um pensamento abstrato, baseado em regras que fundamentam um acordo implicitamente assumido ao entrar no jogo. $\mathrm{Na}$ situação, nota-se também como uma negociação entre mãe e criança gera a possibilidade de enquadrar uma ação em um setting de ação que gera significados, mudança de papéis e regras.

No momento em que a mãe situa o desenho da criança em um mundo imaginário, abre-se a possibilidade de descentrar-se de um dado objetivo, e o desenho, que antes era a representação pictográfica de uma casa, transforma-se em um objeto pertencente a um cenário de história infantil ganhando um novo significado.

Um dos primeiros elementos que podemos analisar neste dado é que, a partir das palavras, criam-se novas possibilidades. Quando a mãe afirma "Ah, já sei! Vai ser a casa de chapeuzinho vermelho", inicia-se a brincadeira de faz-de-conta, que permite situar a casa como parte de um outro cenário que se distingue como sendo o cenário de uma história, incluindo a brincadeira em um outro contexto de interação.

Embora a mãe seja quem nomeia a casa desenhada como sendo a de Chapeuzinho Vermelho, faz-se necessário ressaltar que a entrada da situação imaginária no setting não é apenas resultante da ação da mãe, mas também da possibilidade da criança de compartilhar e reger sua ação lúdica a partir de um significado comum. A entrada da criança no jogo proposto pela mãe aponta para a perspectiva de abandonar um contexto de ação inicial e atuar a partir da inclusão do faz-de-conta trazido pelo interlocutor, mostrando assim, uma flexibilidade de pensamento.

No trecho da interação analisado, verificam-se como as trocas lingüísticas parecem se constituir importantes para a flexibilização e abstração do pensamento infantil. A fala da mãe passa a gerar significados que permitem a criança compartilhar de uma ação com o outro e agir a partir das significações que isto traz ao jogo.

Na literatura, a aquisição de uma teoria da mente é considerada como a capacitação do sujeito a atribuir 
estados mentais a si e aos outros, reconhecê-los como tais e comunicar-se sobre estes. Partindo desta definição, pode-se compreender que atividades como a cooperação e a competição são possibilitadas pela compreensão de que o outro possui desejos, aptidões ou crenças iguais ou diferentes das suas. Então, como afirma Dias (1993, p. 588) a teoria da mente seria "uma compreensão implícita demonstrada nas interações diárias com outras pessoas". É nas relações com os outros sujeitos sociais que a teoria da mente parece não só manifestar-se, mas também emergir.

As interações da criança demonstram não só a importância de uma teoria da mente, mas também apontam para a sedimentação de importantes elementos para a emergência desta. Na situação aqui analisada, observa-se como este tipo de atividade permite à criança uma ação para além do dado concreto e da ação própria para compartilhar o significado trazido pelo outro que interage com ela. Situando sua ação a partir do ponto de vista ou contexto trazido pelo parceiro de jogo, a criança descentra-se do significado dado por ela a seu desenho e inclui a perspectiva do outro. Descentrar-se do próprio conceito, pensamento ou idéia e passar a operar a partir da perspectiva trazida pelo outro é sem duvida uma habilidade que exige considerar o ponto de vista do outro e interpretálo. Esta possibilidade de descentrar-se dos próprios estados mentais e posicionamentos é também condição importante na compreensão e diferenciação dos estados mentais próprios em relação aos de outros agentes sociais. Em resumo, descentrar-se do próprio pensamento é mais que uma ferramenta cognitiva presente na aquisição de uma teoria da mente, é também a possibilidade de assumir um posicionamento distinto frente ao outro, o que implica em aquisições afetivas e sociais.

Uma leitura mais aprimorada dos dados permite perceber que ao compartilhar um sentido para sua própria produção, sentido este que é trazido pela mãe, a criança transcende o mundo privado de construção de significados para partilhar, assumindo o que Valsiner (1997) afirma ser uma capacidade de, nas trocas lingüísticas e na ação, assumir reciprocamente papéis e perspectivas, e de complementar intenções. Ao assumir o significado dado por sua mãe ao desenho, a criança sai do domínio de uma produção pictográfica individual para uma produção que se dá entre dois, em um processo intersubjetivo. E é este compartilhar de significados que enfatizamos como presente no jogo de faz de conta entre a criança e seus parceiros.

Um outro elemento que pode ser destacado como um importante atributo da brincadeira de faz-de-conta para o desenvolvimento de uma teoria da mente é a plasticidade na mudança de papéis que este tipo de jogo favorece. Como comentado anteriormente, quando a situação de faz-de-conta é inserida no jogo, a criança assume diferentes pontos de vista: construtor do cenário, animador da história, platéia que assiste e julga comportamento. A mudança de papéis permite à criança assumir na brincadeira diferentes perspectivas; em alguns momentos, até desenvolver uma ação complementar ou em parceria com a ação do outro. Esta interação com o outro tem como requisito a possibilidade de assumir a perspectiva do outro para assim desenvolver uma performance em consonância com este. Em muitas falas, mãe e criança complementam frases e ação um do outro, interpretam e captam pistas dadas pelo parceiro. Ao complementar papéis sem que haja uma intervenção explicita do outro anunciando as mudanças no jogo, a criança opera dentro de um contexto em que a inferência acerca das intenções e sentidos trazidos pelo outro à brincadeira é condição necessária. Ao complementar o papel desempenhado pelo outro, a criança baseia-se em uma compreensão implícita sobre o que a ação do outro demanda.

Além disto, a brincadeira de faz-de-conta parece gerar o que chamaremos de um acordo comunicativo em que junto com o outro se negocia o enredo da brincadeira (que situação imaginária fundamentará a brincadeira? Que personagens serão incluídos?). Ao chamar isto de um acordo comunicativo não estamos considerando que ele ocorre sempre verbalizado ou combinado entre mãe e criança, ou entre criança e qualquer outro participante. Este pode ser produzido a partir de pistas contextuais, tais como olhares, fala da criança ou da mãe e seus personagens (Bretherton, O'Connell, Shore \& Baltes, 1984).

$\mathrm{Na}$ situação aqui analisada, a mãe dá um sentido ao desenho e a partir daí são realizados ajustes até que Igor e sua mãe compartilham a brincadeira dentro das regras do script negociadas e estabelecidas por ambos.

Um último aspecto a ser destacado é que, na situação da brincadeira, quando a mãe questiona a possibilidade de "abrir a porta para o lobo", (já que a porta é desenhada e na ordem do real objetivo não pode ser aberta) abre-se uma lacuna na qual mãe e criança atuam em dois domínios diferentes, o da realidade objetiva e o do "mundo imaginário". Igor preenche este hiato negociando com a mãe o significado daquela ação proposta (se não é possível no real, ali, brincando de faz-de-conta é possível e assim a história poderia continuar a se desenrolar). Argumentar com a mãe defendendo a possibilidade da ação proposta é uma atividade que parece se 
basear na compreensão de que o outro, com quem a criança interage, está assumindo um ponto de vista ou uma opinião diferente, e que, portanto, precisa ser convencido com argumentos. Igor argumenta com a mãe dentro do script da história, convencendo-a a produzir de forma imaginária uma cena da qual as outras dependem. Nesta negociação, observa-se o desenvolvimento de um espaço entre mãe e criança que Bruner (1997) e outros autores denominam de uma psicologia popular.

\section{CONCLUSÃO}

É importante ressaltar que, embora ao longo deste estudo, tenham sido desenvolvidas relações entre o uso de algumas ferramentas sociais em uma brincadeira de faz-de-conta e o desenvolvimento de características compreendidas como parte do desenvolvimento de uma teoria da mente, este trabalho não se detém na discussão sobre a presença ou ausência de uma teoria da mente na criança aqui estudada.

O que talvez seja relevante neste estudo é trazer evidências de como em interações do dia-a-dia com outros sujeitos sociais, a criança lança mão de recursos importantes no desenvolvimento social, afetivo e cognitivo que demonstram claramente um processo em que a criança situa-se e é ao mesmo tempo reconhecida por outros como sujeito social.

Como ressaltado, embora neste estudo não tenhamos a pretensão de provar a presença ou ausência de uma teoria da mente por parte da criança, consideramos importante destacar como habilidades presentes e requeridas na brincadeira de faz-de-conta são parte da sedimentação de habilidades definidas na literatura como parte de uma teoria da mente.

Estas habilidades têm suma importância para estudos da teoria da mente em vários tópicos, tais como a gênese de uma teoria da mente, em que as relações sociais parecem ter papel fundamental. Um outro elemento relevante é a possibilidade de perceber que, embora neste caso estudado, a mãe tenha um papel ativo e intervenha como sujeito mais experiente, a criança não exerce um papel passivo, mas negocia, questiona e defende a possibilidade de inserir elementos na interação. Este fato abre espaço para a discussão do processo de socialização da criança. Atendo-se ao caso discutido, nota-se que a criança não tem apenas sua ação modulada pelo adulto, mas também é sujeito ativo na relação com o mundo social, mostrando assim, que o processo que dá origem ao sujeito social, mais que uma imersão na cultura, é um processo dialético que se modifica em cada relação significante.

\section{REFERÊNCIAS}

Alves, A. C. S. (2003). Uso de termos mentais por crianças de 2 a 5 anos em interação com suas mães e pares. Dissertação de Mestrado Não-Publicada, Programa de Pós-Graduação em Psicologia Cognitiva, Universidade Federal de Pernambuco,Recife.

Bretherton, I., O'Connell, B., Shore, C. \& Bates, E. (1984). The effect of contextual variation on symbolic play and development of social understanding. New York: Academic.

Bruner, J. (1997). Atos de significação. Porto Alegre: Artes médicas.

Bruner, J. (1986). El habla del niño: cognición y desarrollo Humano. Barcelona: Paidós.

Dias, M. G. B. B. (1993). O desenvolvimento do conhecimento da criança sobre a mente. Psicologia: Teoria e Pesquisa, 9, 587600 .

Dias, M. G. B. B. \& Harris, P. L. (1988a). The effect of makebelieve play on deductive reasoning. British Journal of developmental Psychology, 6, 207-221.

Dias, M. G. B. B. \& Harris, P. L. (1988b). Realidade e fantasia: sua influência no raciocínio dedutivo. Psicologia: Teoria $e$ Pesquisa, 4(1), 55-88.

Dias, M. G. B. B. \& Harris, P. L. (1989). O efeito da brincadeira de faz-de-conta no raciocínio da criança. Arquivos Brasileiros de Psicologia, 41(2), 95-105.

Dias, M. G. B. B. \& Harris, P. L. (1990a). A Influência da imaginação no raciocínio das crianças. Arquivos Brasileiros de Psicologia, 42(1), 95-105.

Dias, M. G. B. B. \& Harris, P. L. (1990b). Regras morais e convencionais no raciocínio das crianças. Psicologia: Teoria e Pesquisa, 6(2), 125-138.

Dias, M. G. B. B. \& Harris, P. L. (1990c). The influence of the imagination on reasoning by young children. British Journal of Developmental Psychology, 8, 305-318.

Furtado, O. (2002, $2^{\text {a }}$ Ed.). O psiquismo e a subjetividade social. Em A. M. B. Bock, M. G. M. Gonçalves \& O. Furtado (Orgs.). Psicologia sócio-histórica: uma perspectiva em psicologia. São Paulo: Cortez.

Jou, G. I. \& Sperb, T. M. (1999). Teoria da Mente: diferentes abordagens. Psicologia: Reflexão e Critica. 12(2). Disponível em: < http://www.scielo.br/ prc>. (Acesso em 02/07/2004).

Leslie, A. M. (1987). Pretense and representation: The origins of the "theory of mind". Psychological Review, 94, 412-426.

Leslie, A. M (1988a). Some implications of pretense for mechanisms underlying the child's theory of mind. In J. Astington, P. Harris \& D. Olson (Eds.), Developing theories of mind. Cambridge: University.

Leslie, A. M. (1988b). The necessity of illusion: Perception and thought in infancy. In L. Weiskrant (Eds.), Thought without language. Oxford: University.

Piaget, J. (1929). The Child's conception of the world. (J. Tomlinson \& A. Tomlinson, Trad.). London: Kagan Paul. 
Piaget, J. (1956). A Linguagem e o pensamento da criança. Rio de Janeiro: Fundo Cultural.

Pomerantz, A. \& Fehr, B. J. (1997). Conversation analysis: An approach to the study of social action as sense making practice. In T. Van Dijik (Ed.), Discourse as social interaction. London: Sage.

Shats, M., Silber \& Wellman, H. M. (1993). The acquisition of mental verbs: A systematic investigation of the first reference to the mental states. Cognition, 14, 301-321.

Silva, L. S. P., Guimarães, A. B., Vieira, C. E., Franck, L. N. S. \& Hippert, M. I. S. (2005). O brincar como portador de significados práticos e sociais. Revista do Departamento de
Psicologia - UFF, 17(2). Disponível em: < http:// www.scielo.br/prc.>. (Acesso em 10/11/2006).

Valsiner, J. (1997). A construção subjetiva da intersubjetividade. Interfaces: Revista de Psicologia, 1(1), 41-44.

Recebido em 01/02/2005 Aceito em 28/11/2005

Endereço para correspondência: Ana Claudia da Silva Alves. Rua Santo Elias, 433, ap. 1901, CEP 52020-090, Recife-PE. E-mail: cacaunani@gmail.com 